\title{
EXPERIMENTAL AND ANALYTICAL ASSESSMENT OF RACKING RESISTANCE OF PARTIALLY ANCHORED TIMBER FRAME WALLS
}

\author{
R. STEENSELS ${ }^{1}$, K. DE PROFT ${ }^{2} \&$ B. VANDOREN ${ }^{1}$ \\ ${ }^{1}$ Hasselt University - Faculty of Engineering Technology, Martelarenlaan, Hasselt, Belgium. \\ ${ }^{2}$ WOOD. BE - Belgian Institute for Wood Technology, Hof ter Vleestdreef, Belgum.
}

\begin{abstract}
The resistance to horizontal loads provided by timber constructions is determined by the racking resistance of the timber frame walls within the structure. In Eurocode 5 (EN 1995-1-1), two methods are described to assess the racking resistance of these structural elements. Method A refers to a mechanical model while method B is empirically based and therefore less attractive. When using method A, full anchorage of the leading stud is needed. Moreover, contributions of wall panels with openings are neglected in the assessment of the racking resistance. In this paper, an experimental campaign studying the racking resistance of partially anchored walls with different wall and loading configurations is presented. The study shows that window and door openings lead to a reduction of the racking resistance of the wall depending on the size of the opening. Additionally, a comparison between the experimental data and several design methods for the assessment of the racking resistance of the wall panels is made.
\end{abstract}

Keywords: experimental campaign; racking resistance; timber frame wall panels.

\section{INTRODUCTION}

Correct assessment of the racking resistance of timber frame wall panels is of great importance during the structural analysis of timber structures. Eurocode 5 (EN 1995 1-1, EC5) [1] provides two different methods for the calculation of the resistance to horizontal forces for timber frame wall panels. Method A is based on a mechanical model, whereas method B is an empirically based model. Method A forces the designer to apply full anchorage of the leading stud of the wall, necessitating the use of tie-downs to ensure proper anchorage. In turn, high reaction forces are induced at the bottom of the leading stud leading to an intricate design of the joint of this wall panel. Furthermore, EC5 does not allow for the inclusion of wall panels with openings in the analysis of the racking resistance. Any wall panel with a door or window opening is to be neglected in the assessment of the total racking resistance of the full wall.

Modern timber constructions often involve more open floor plans with a considerable amount of openings in the wall panels. A more advanced method for the assessment of the racking resistance can therefore optimise the design of these structures and minimise the material usage. In this paper, an experimental campaign is presented for the assessment of the racking resistance of partially anchored, timber frame walls. The total racking resistance of a range of walls consisting of multiple wall panels, with and without openings and with different load characteristics is investigated and compared to different analytical methods available in the literature.

\section{DESIGN MODELS FOR PARTIALLY ANCHORED WALLS}

As previously mentioned, EC5 does not allow for the calculation of the racking resistance of partially anchored walls. More recently, several analytical models have been developed which also allow for the assessment of the racking resistance of partially anchored walls. 
Two models will be discussed in this paper. A perfectly plastic model suggested by Källsner and Girhammar [2,3] and the simplified model suggested by De Proft [4].

\subsection{Källsner and Girhammar model}

The calculation of the racking resistance proposed by Källsner and Girhammar [2] is based on the static theorem which states that a load case satisfying the equilibrium conditions of the structure and yield condition of the applied materials is acceptable and conservative. The connectors are assumed to behave perfectly plastic in order to provide a lower bound value for the racking resistance. Furthermore, the fasteners are assumed to be distributed evenly along the perimeter of each individual wall panel. Consequently, the capacity of the connections can be expressed as a force per unit length:

$$
\mathrm{f}_{\mathrm{p}}=\frac{F_{y}}{S}
$$

where $\mathrm{f}_{\mathrm{p}}$ is the capacity of the fasteners in $\mathrm{N} / \mathrm{mm}, F_{y}$ is the yielding load of an individual fastener and $S$ equals the spacing of the fasteners.

\subsubsection{Walls without openings}

To assess the racking resistance of timber frame wall elements without openings, consider the partially anchored wall presented in Figure 1. In the analysis procedure of Källsner and Girhammar [3], the wall is divided in two parts. In the first part, uplift of the vertical studs can occur and the forces are transferred from the frame structure to the substrate via the connections with the sheathing material. In the second part, the wall panels are assumed to be fully anchored. As
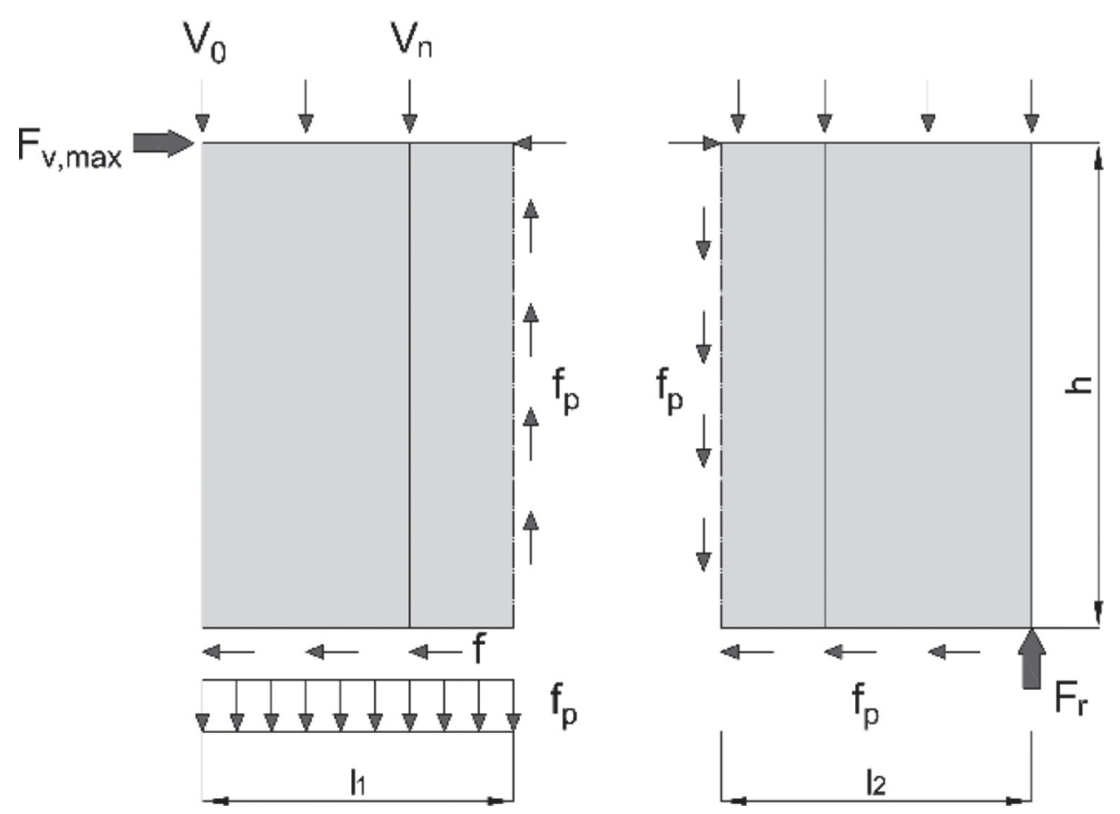

Figure 1: Källsner and Girhammar design model for walls without openings. 
a result, the forces are distributed to the substrate directly via the frame structure. The racking resistance $\left(F_{v, \text { max }}\right)$ of the wall can be determined using the following equations:

$$
\begin{gathered}
F_{v, \max }=f_{p} \cdot l_{\mathrm{eff}} \\
l_{\mathrm{eff}}=\left(\frac{l_{1}}{2 h}+\frac{V_{e q}}{f_{p} h}\right) l_{1}+l_{2} \\
\mathrm{~V}_{\mathrm{eq}}=\sum_{i=0}^{n}\left(\frac{l_{1}-x_{i}}{l_{1}} V_{i}\right)
\end{gathered}
$$

In these equations, $l_{\text {eff }}$ describes the length of the wall which will effectively contribute to the horizontal strength. $l_{1}$ and $l_{2}$ are, respectively, the length of the partially anchored and fully anchored wall sections. $h$ represents the total height of the wall. $V_{e q}$ is the equivalent vertical load on the leading stud of the wall and $x_{i}$ equals the length between the leading stud and the vertical stud to which an additional vertical load $V_{i}$ is applied.

\subsubsection{Walls with openings}

When an opening is introduced in the wall, the same basic strategy is applied. The wall is divided into segments left and right of each opening (Fig. 2). Each part is evaluated comparable to the method applied for walls without openings. However, additional contributions to the total racking resistance resulting from the panels with the openings are also included in the analysis. An example of such a wall is presented in Figure 2. Figures 3 and 4 present the force distribution on which the design model is based.

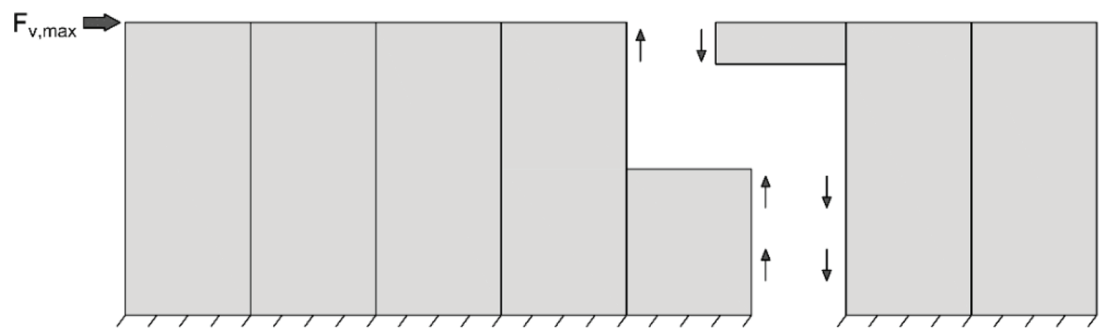

Figure 2: Wooden frame wall with opening.
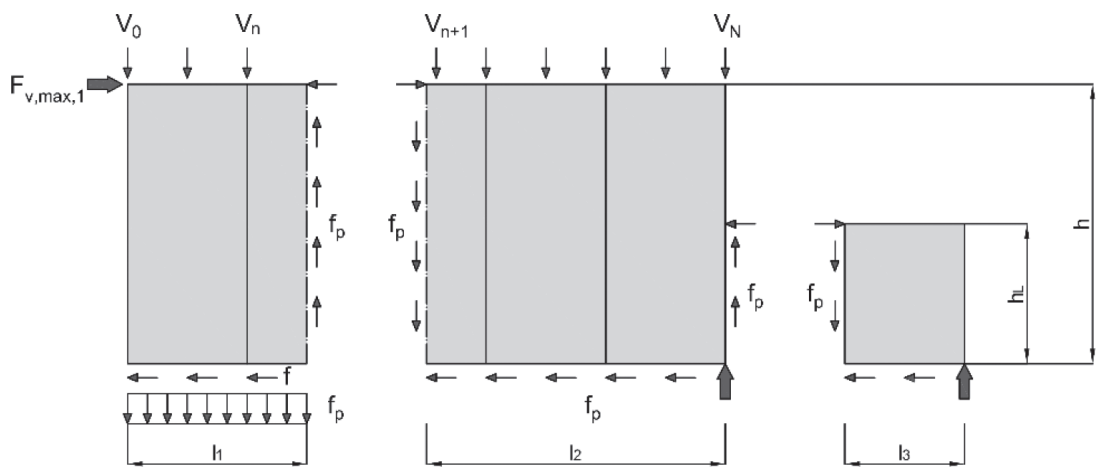

Figure 3: Källsner and Girhammar design model for wall panels left side of the opening. 

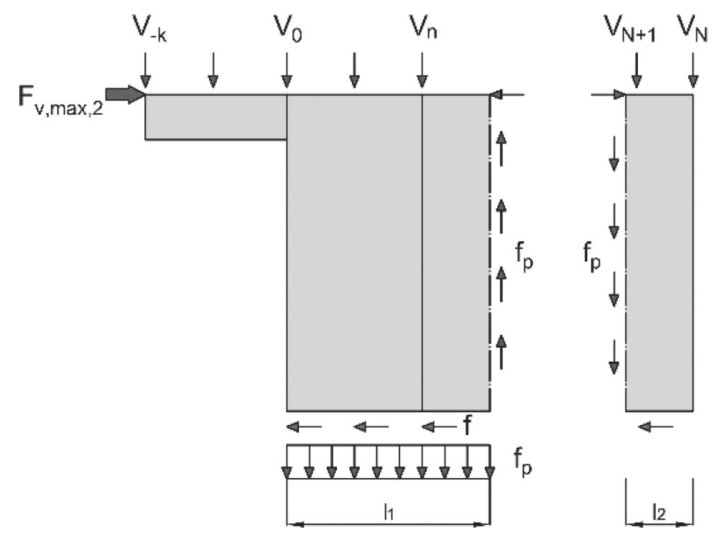

Figure 4: Källsner and Girhammar design model for wall panels right side of the opening.

The racking resistance of the wall segment to the left of the opening is computed using the following equations:

$$
\begin{aligned}
& l_{1}=h\left(1-\frac{\sum_{i=0}^{N} V_{i}}{f_{p} h}\right) \\
& l_{2}=l_{l}-l_{1} \\
& \mathrm{~V}_{\mathrm{eq}}=\sum_{i=0}^{N}\left(\frac{l_{1}-x_{i}}{l_{1}} V_{i}\right) \\
& l_{\mathrm{eff}, 1}=\left(\frac{l_{1}}{2 h}+\frac{V_{e q}}{f_{p} h}\right) l_{1}+l_{2}+\frac{f_{l}}{f_{p}} \frac{h_{l}}{h} \lambda l_{3} \\
& \lambda=\min \left\{\begin{array}{c}
\frac{f_{l}}{f_{p}} \frac{h}{l_{3} h}\left[\left(1-\frac{l_{1}}{2 h}-\frac{V_{e q}}{f_{p} h}\right) l_{1}+\frac{n_{y} F_{y}}{f_{p}}\right] \\
\frac{f_{l}}{f_{p}} \frac{2 h}{l_{3}\left(h-h_{l}\right)}\left[\left(\frac{l_{1}}{2 h}-\frac{V_{e q}}{f_{p} h}\right) l_{1}+l_{2}\right] . \\
\frac{f_{l}}{f_{p}} \frac{b_{p 1}}{l_{3}}
\end{array}\right. \\
& F_{v, \max , 1}=f_{p} \cdot l_{\text {eff }, 1}
\end{aligned}
$$

with $l_{l}$ representing the length of the wall segment to the left of the opening, $f_{l}$ equals the capacity of the connections $[\mathrm{N} / \mathrm{mm}]$ at the wall panel below the opening. $h_{l}$ and $l_{3}$ is the height and length of the wall panel below the opening, $n_{y}$ and $F_{y}$ equal the number and capacity of the connections attached to the upper horizontal beam, and. $b_{p 1}$ is the width of a single wall panel. 
The wall segment to the right of the opening is evaluated as follows:

$$
\begin{gathered}
l_{1}=h\left(1-\frac{\sum_{i=0}^{N} V_{i}}{f_{p} h}\right) \\
\mathrm{V}_{\mathrm{eq}}=\sum_{i=0}^{N}\left(\frac{l_{1}-x_{i}}{l_{1}} V_{i}\right) \\
l_{\text {eff }, 2}=\left(\frac{l_{1}}{2 h}+\frac{V_{e q}}{f_{p} h}\right) l_{1}+l_{2} \\
F_{v, \max , 2}=f_{p} \cdot l_{\text {eff }, 2} \\
F_{v, \max , t o t}=F_{v, \text { max }, 1}+F_{v, \max , 2}
\end{gathered}
$$

\subsection{De Proft model}

The analyses method for partially anchored walls suggested by De Proft [4] is also based on the static theorem (lower bound) and starts from the load distribution of a single-wall panel (Fig. 5).

The maximum capacity in the connections at the bottom of the panel is described by:

$$
\mathrm{f}_{\mathrm{p}}=\frac{F_{y}}{s}=\sqrt{u_{1}^{2}+v^{2}}
$$

From eq 16 and the rotational equilibrium of the panel, the racking resistance $F_{v, \max }$ of the wall is determined to be equal to

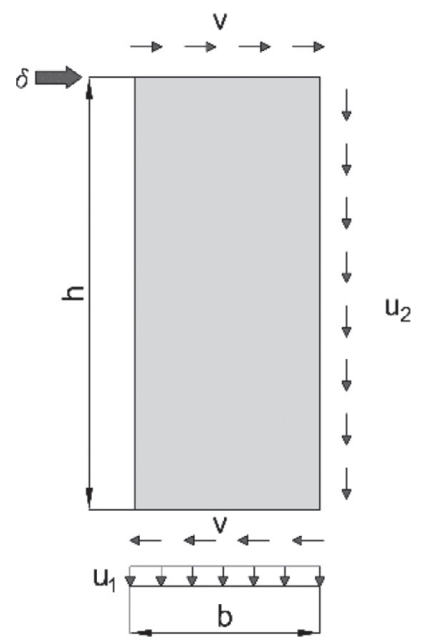

Figure 5: Load distribution of a partially anchored wall panel under horizontal load. 


$$
\mathrm{F}_{\mathrm{v}, \max }=\frac{F_{y} \cdot b}{s \cdot \sqrt{1+\left(\frac{2 h}{b}\right)^{2}}}
$$

The calculation of the racking resistance alters when the wall is constructed of multiple wall panels. For these walls, De Proft provides a complex and simplified method for the assessment of the racking resistance. The complex method involves a more exact computation of the racking resistance. The anchoring force $u_{2}$ in the end stud of the previous wall panel is evaluated together with the racking resistance of the observed wall panel using a system of equilibrium equations. However, a simplified method is also suggested in which eq 17 is applied and the width $b$ of the entire wall instead of a single-wall panel is used. It is stated that this approach provides an efficient assessment of the racking resistance with an acceptable rate of error in comparison with the exact solution [4].

The method proposed by De Proft only evaluates the racking resistance for wall panels without openings. A panel ratio based on the work of Sugiyama [5] and Yasumura [6] is applied in order to take the influence of openings into account. This panel ratio $(r)$ is developed using an experimental and numerical campaign and re-evaluates the racking resistance of the wall taking into account the geometrical properties of the opening $\left(\mathrm{F}_{\mathrm{v}, \max , \mathrm{o}}\right)$. The following equations are applied:

$$
\begin{aligned}
& \mathrm{F}_{\mathrm{v}, \text { max }, \mathrm{o}}=Q \cdot F_{v, \text { max }} \\
& Q=\left\{\begin{array}{cl}
r & \text { Fully anchored } \\
\frac{r}{2-r} & \text { Partially anchored }
\end{array}\right. \\
& r=\frac{1}{1+\frac{\alpha}{\beta}} \\
& \alpha=\frac{a_{o} \cdot b_{o}}{L \cdot h} \\
& \beta=\frac{\sum b_{p 2}}{L}
\end{aligned}
$$

where $\mathrm{Q}$ represents the racking resistance ratio. $\mathrm{r}$ equals the panel ratio. $\alpha$ and $\beta$ are dimensionless parameters taking into account the width $\left(a_{\mathrm{o}}\right)$ and height $\left(b_{o}\right)$ of the openings, the total length of the wall $(L)$, height of the wall $(h)$ and the sum of the width of the wall panels without openings $\left(b_{p 2}\right)$.

\section{EXPERIMENTAL CAMPAIGN}

\subsection{Test set-up}

An experimental campaign has been performed investigating the racking resistance of partially anchored wooden frame wall panels [7]. Eleven different panel configurations (Fig. 6) 


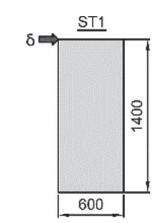

ST3DL
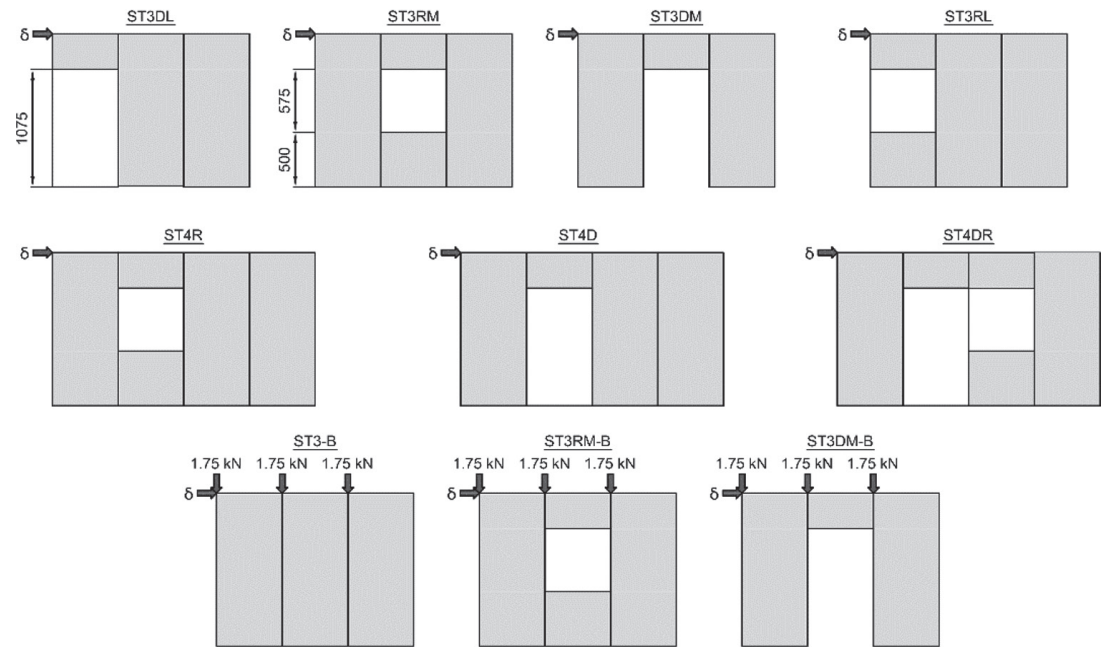

Figure 6: Wall configurations of test specimens.

are tested. Additionally, a different load configuration is applied to three panel configurations leading to the assessment of the total racking resistance of 14 test specimens.

The walls are constructed on a 1:2 scale. The height of the elements is $1400 \mathrm{~mm}$, the width of each wall panel is $600 \mathrm{~mm}$. The different wall configurations consist of up to four wall panels so the width of the walls ranges from 600 to $2400 \mathrm{~mm}$. The timber used in the timber frame is classified C24. However, the density of the timber is higher than the density expected for $\mathrm{C} 24$. The cross-section of the beam elements measure $50 \mathrm{~mm} \times 70 \mathrm{~mm}$. The distance between each vertical stud is $300 \mathrm{~mm}$. The sheathing material consists of particle boards type P5 with a thickness of $12 \mathrm{~mm}$. The wall panels are connected to the wooden frame structure using $1.70 \mathrm{~mm} \times 1.88 \mathrm{~mm}$ staples with a length of $50 \mathrm{~mm}$. The spacing between the connectors is $150 \mathrm{~mm}$ for the outer studs of each individual panel. The spacing in the middle stud is $300 \mathrm{~mm}$. Door openings have a height of $1075 \mathrm{~mm}$. The height of window openings is 575 $\mathrm{mm}$. Each wall is anchored to the substrate using 3 screws along the first $300 \mathrm{~mm}$ of the bottom bar. In the remainder of the bottom rule, two screws every $300 \mathrm{~mm}$ are provided for additional anchorage to the substrate.

The racking resistance of each wall configuration is determined in accordance with EN 594 [8] and equals the maximum registered horizontal force during a horizontal displacement (d) of $100 \mathrm{~mm}$. The horizontal displacement is applied at the top left corner of the test specimen and measured at the top and bottom bar of the wall. The vertical displacement of the leading stud is also measured. For some wall configurations (ST3-B, ST3RM-B, ST3DM-B), an additional vertical load of $1.75 \mathrm{kN}$ is applied to the leading stud of each wall panel.

Figure 7 presents the experimental set-up of the ST3 and ST3-B wall configurations. Guiding beams have been placed at the top of the test set-up at both sides of the test specimen (Fig. 7a). Rollers are applied between the guiding beams and the wall specimens to ensure that no out of 


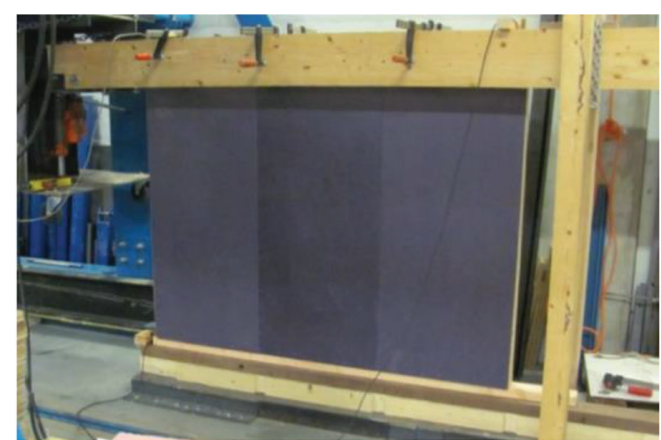

(a)

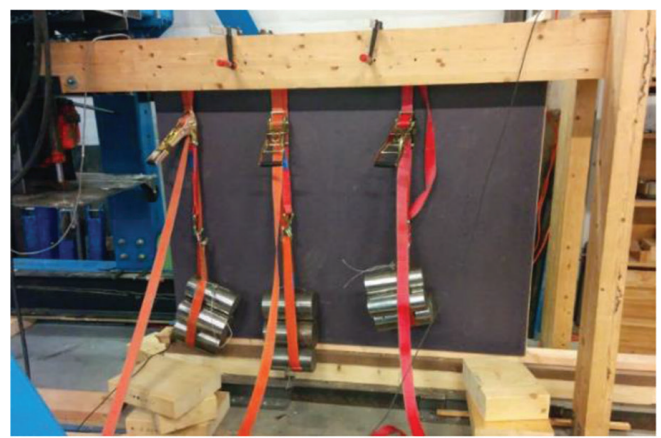

(c)

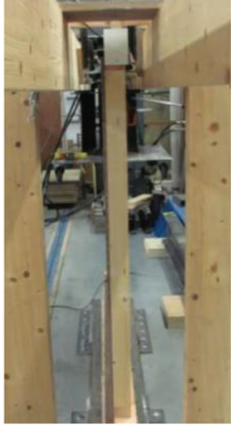

(b)

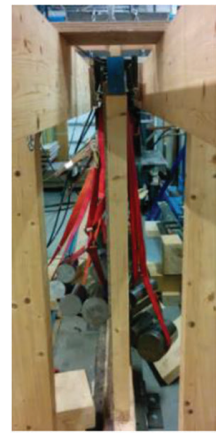

(d)

Figure 7: Experimental test set-up.

plane movement occurs during the test (Fig. 7b). Figure 7c and d present the load configuration of the ST3-B specimen. A vertical force of $1.75 \mathrm{kN}$ is applied to the leading stud of each individual wall panel by applying a strap with weights over the wall at the location of the studs.

\subsection{Experimental results}

The load-displacement diagrams resulting from the tests are presented in Figure 8. The displacement is measured at the top of the wall. Figure 8 a compares the racking resistance of wall specimens with increasing width and without openings. As expected, the larger wall specimens provide a larger total racking resistance.

Figure $8 \mathrm{~b}$ shows the load-displacement diagrams of the wall specimens constructed of three wall panels. A clear influence of the presence of an opening on the racking resistance of the specimen can be seen. The racking resistance of the walls with three panels drops to $60 \%$ of the original strength when a door opening is introduced in the wall. A window opening causes a decline of the racking resistance to $85 \%$ compared to a wall without openings. Furthermore, Figure $8 \mathrm{~b}$ shows that the location of the door or window opening has a negligible influence on the racking resistance.

Figure $8 \mathrm{c}$ shows that the behaviour of the test specimen consisting of 4 wall panels. The racking resistance for the wall panels with a door and window opening drops to values of 


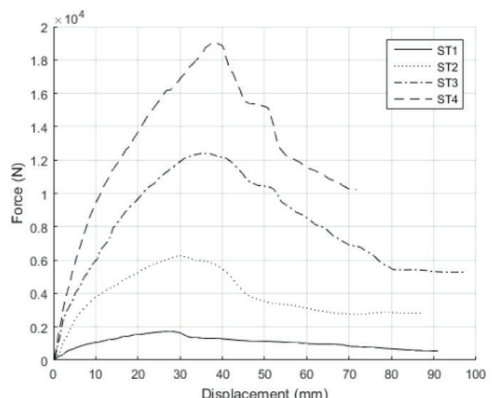

(a)

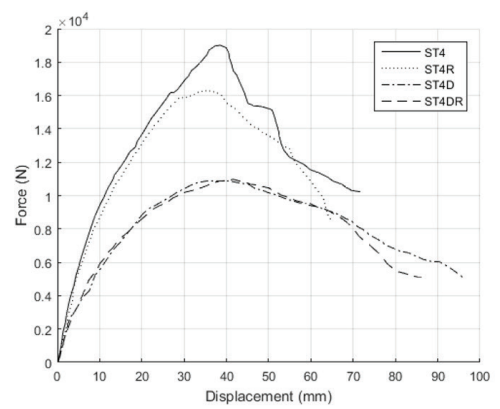

(c)

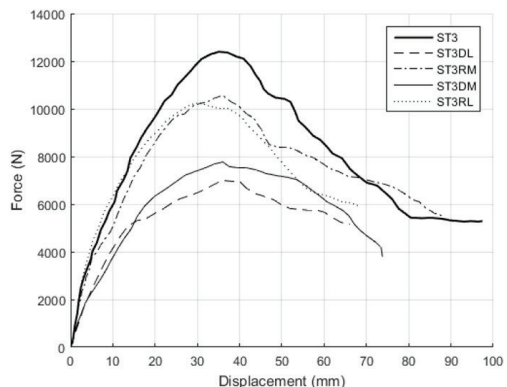

(b)

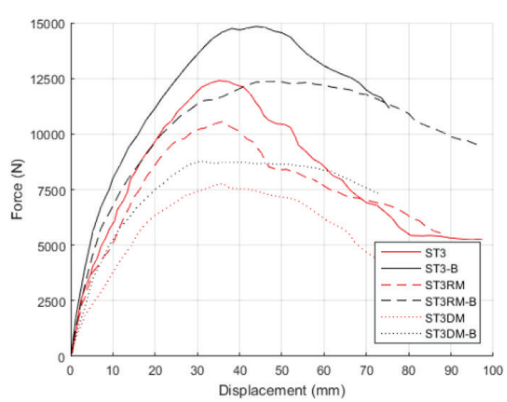

(d)

Figure 8: Force-displacement diagrams of wall configurations.

$57 \%$ and $85 \%$, respectively. This is very similar to the influence of the openings in the specimen with three wall panels. Remarkably, the racking resistance of the ST4D and ST4D+R specimens is also very similar even though the total size of the opening in the ST4D+R test specimen is considerably larger.

Figure $8 \mathrm{~d}$ shows the influence of a vertical load on the racking resistance of a partially anchored timber frame wall. It is apparent that this vertical load provides additional anchorage to the leading studs of the individual wall panels. A higher total racking load is expected. An increase in racking load is clearly noticed, but the influence is not very high. The vertical load is only a fraction of the load needed for full anchorage. Due to the openings of the wall, the influence gets even smaller.

\section{COMPARISON BETWEEN EXPERIMENTAL AND ANALYTICAL MODELS}

Figure 9 presents the comparison between the experimental data and the results of the plastic model of Källsner and Girhammar, and the simplified model of De Proft combined with the panel ratio of Yasumura to take into account the openings in the wall panels. It can be seen that the combination of the simplified model proposed by De Proft in combination with the panel ratio found in the work of Yasumura provides better agreement with the experimental readings in comparison with the model of Källsner and Girhammar. However, considerable discrepancies between the experimental and analytical data can still be distinguished for some test specimens (e.g. ST3-RL, ST4D+R). Furthermore, the analytical methods lead to both over- and underestimated values of the racking resistance. Therefore, the analytical methods do not always lead to conservative design. 


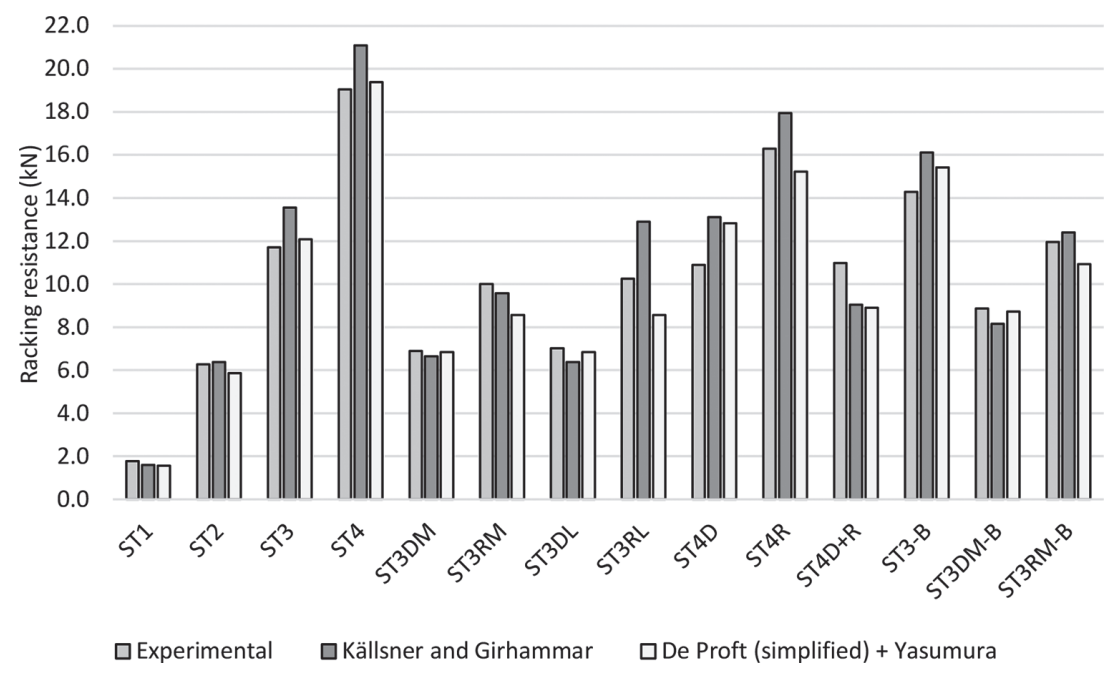

Figure 9: Comparison between experimental and analytical data.

\section{CONCLUSIONS}

This paper presents an analytical and experimental campaign for the evaluation of the racking resistance of partially anchored timber frame walls. Two analytical methods for the assessment of the racking resistance, found in the available literature, are presented and compared to experimental data of 14 test specimens. Both the influence of openings in the wall panels and presence of additional vertical loads on the studs of timber frame are included. It is concluded that the openings in wall panels decrease the total racking resistance of the walls based on their size. The location of the opening was found to have a negligible influence. The presence of a vertical load on the studs of the timber frame causes additional anchorage of the wall panels. As a result the racking resistance will increase. Considering the analytical assessment of the racking resistance, it is found that the simplified method of De Proft combined with the panel ratio of Yasumura provides a better agreement with the experimental data compared to the method suggested by Källsner and Girhammar. However, considerable differences between experimental and analytical data can still be identified for some test specimens.

\section{REFERENCES}

[1] EN 1995-1-1, Eurocode 5: Design of timber structures - Part 1-1: General - Common rules and rules for buildings, 2005.

[2] Källsner, B. \& Girhammar, U.A., A plastic lower bound method for design of woodframed shear walls. Proceedings 8th World Conference on Timber engineering. Finland, 14-17 June 2004.

[3] Källsner, B. \& Girhammar, U.A., A plastic design method for incompletely anchored wood-framed wall diaphragms. 9th World Conference of Timber Engineering. Portland Oregon USA, 6-10 August 2006.

[4] De Proft, K. Stability of timber constructions: derivations of typical solutions part II: Horizontal stability of timber frame walls, Wood.be, 2013. 
[5] Sugiyama, H. \& Matsumoto T., Empirical equations for the estimation of racking strength of a plywood shear wall with openings. Summary of Technical Papers, Annual Meetings, Trans of A.I.J. Japan, 1994.

[6] Yasamura, M., Racking resistance of panel-sheathed shear walls with opening, Department of Environment and Forest Resources Science, Shizuoka University. Japan, 2010.

[7] Reweghs K., Schrankweerstand van houtskeletwanden: invloed van raam-en deuropeningen, Master thesis, Hasselt University, 2015.

[8] Bureau for Standardisation, NBN EN 594: Timber structures - test methods - Racking strength and stiffness of timber frame wall panels, Brussels, 2011. 